Asylum and Mental Hospital Reports for $1918-19$ received :

Brighton County.

Carmarthen, Cardigan and Pembroke.

Down District.

Essex and Colchester.

Hants.

Monmouthshire.

Retreat, York.

Roxburgh District.

Salop and Borough of Wenlock.

Also the following Reports :

Neurological Institute of New York, 19r8.

Craig Colony for Epileptics, t919.

Medical Research Committee: "Influence of Alcohol on Manual Work, etc.," 19 tg.

Metropolitan Asylums Board, 1918.

Board of Control for Scotland, 1918.

State Hospital for the Insane, Warren, Pennsylvania, 1918.

Lunacy Reports, Burma, 1918.

Egypt-Lunacy Division, 1918.

The following pamphlets have been received:

Étude-critique sur l'Evolution des Idées relatives a la nature des Hallucinations. Vraies, Dr. Raoul Mourgue.

El Psicoanalisis, par Honorio F. Delgado. 
JOUKNAL OF MENTAL SCIENCE, JANUARY, 1920.

\section{BOREATTON PARK.}

Founded by the late $W$. H. O. SankeY, M.D., F.R.C.P., for the reception of a limited number of ladies and gentiemen mentally afflicted, and now conducted on the same lines by his son, L. H. O. SANkeY, M.A., M.B., B.C.Cantab.

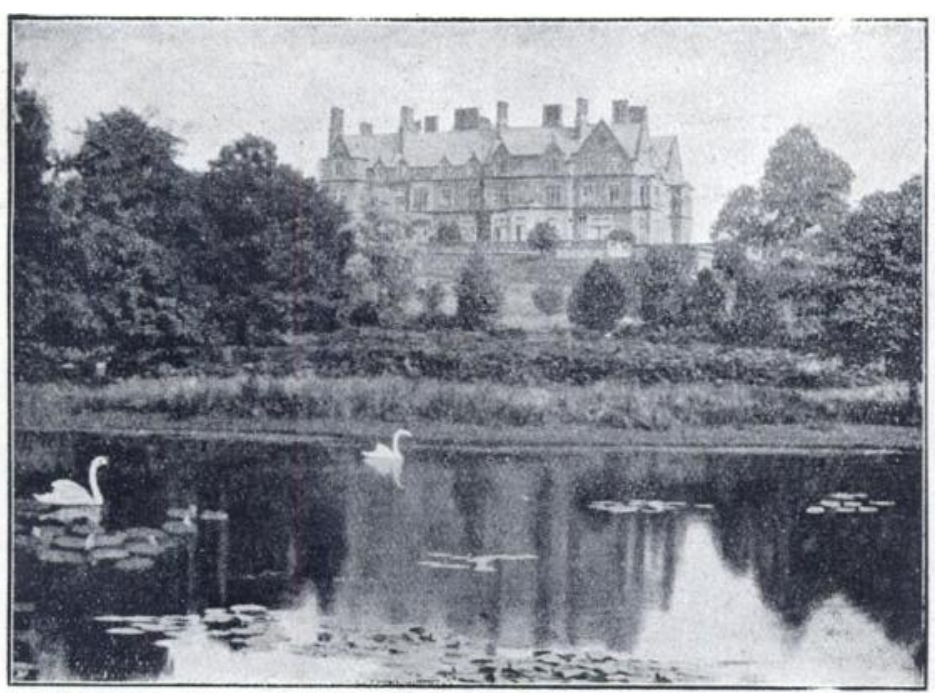

The house, a first-class country Mansion, specially adapted for its purpose, stands about $400 \mathrm{ft}$. above the sea and commands magnifcent views of IVelsh mountain scenery.

The Gardens slope to the West, and lead to the Deer Park, one of the oldest in the kingdom.

There is fishing both for trout and coarse fish in the pools in the Deer Park, and the right of fishing in about 5 miles of the River Perry is leased.

There are Hot Houses and Orchard House.

Private Golf Course of 18 holes, Tennis Courts, and Croquet Lawns.

- So far as possible the patients of both sexes take their meals and associate at all times with the family of the Superintendent, the object being to make the house as much as possible like an ordinary country house.

Arrangements can be made for friends of the Patients to reside in the house should they desire to do so.

There is good stable accommodation, and Horses, Carriages and Motor are provided.

For further particulars applyDr. SANKEY, Boreatton Park, Baschurch, Salop. 


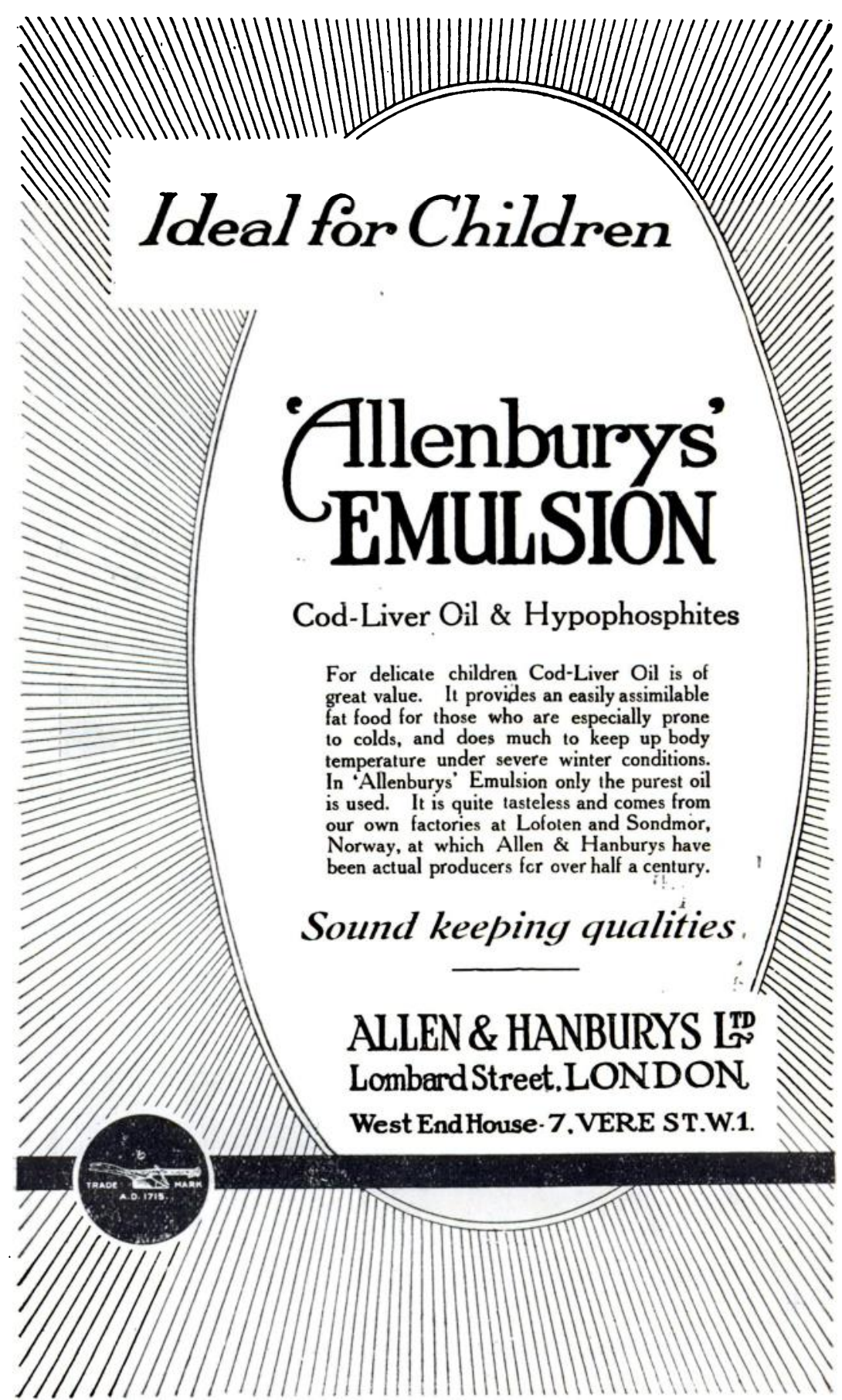




\section{BORDERLAND PATIENTS.}

\section{SOUTH BEACON}

\section{Hadlow Down,}

Nr. Uckfield, Sussex.

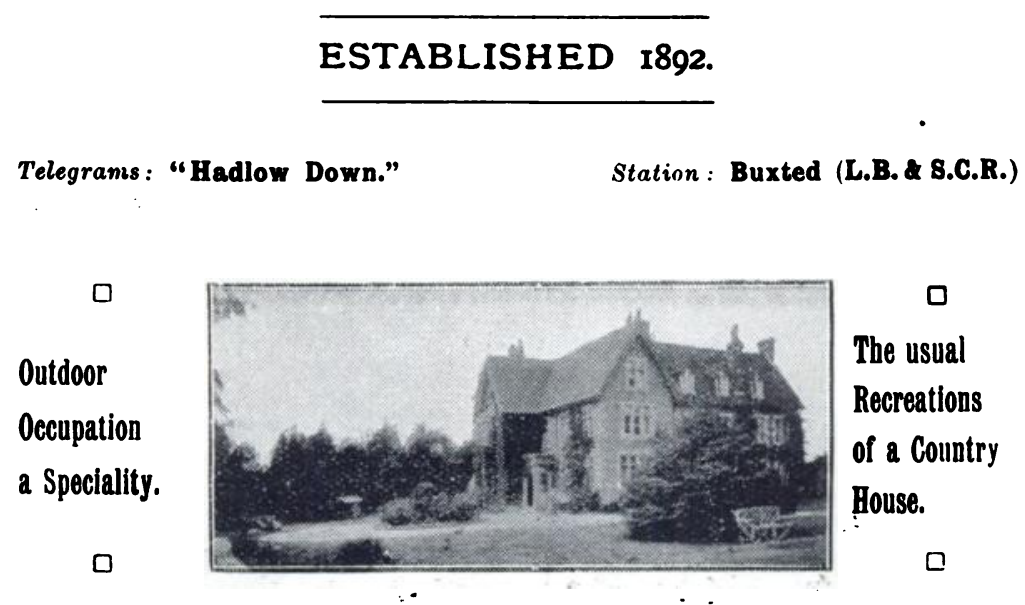

For the reception of 15 gentlemen requiring rest and quietness, but who are not ill enough for certificates.

Terms from 5 Guineas per week.

Full particulars from :: :: PHILIP H. HARMER. 


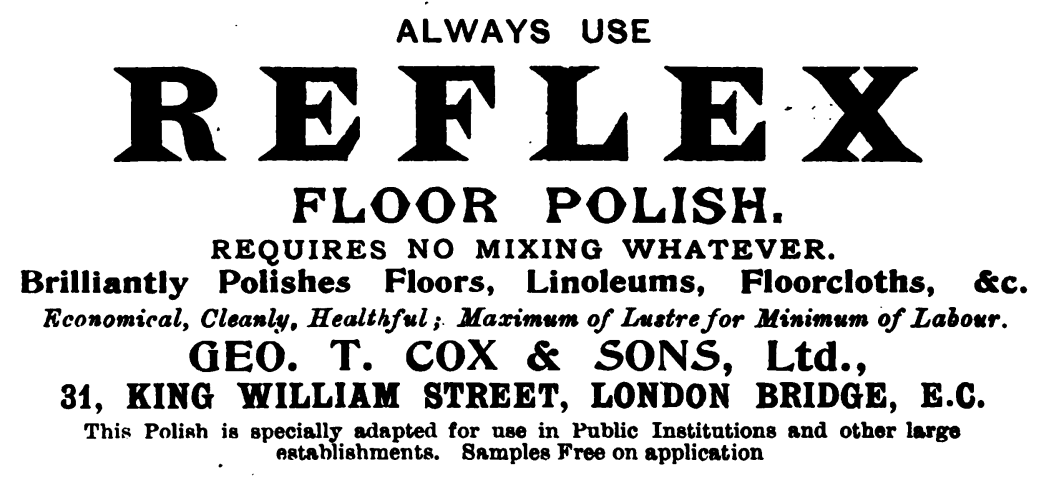

